\title{
HOW TO USE THE COLOR NAME CHARTS 1 TO $34^{\circ}$
}

Given: Munsell notation of the sample.

Required: The color designation.

First, turn to the particular name chart referring most closely to the Munsell hue notation of the sample (see numbers at top of chart); or, if the hue is equally close to two successive charts, use them both.

Second, find the point on the chart defined by the Munsell value and Munsell chroma of the sample; or, if two charts are to be used, plot the point on both of them. Note that the chroma scale is expanded for chromas less than 1.5; see vertical double line on each chart.

Third, read the color designation of the block within which the point falls. If the point falls on a boundary between blocks, read color designations of all blocks touching the point. If, when two charts are to be used, the second chart yields a different designation from the first, read them both.

a Acknowledgment is made to Miss Dorothy Nickerson, individual member of the Inter-Society Color Council, for suggesting the present simple form of these name charts. 

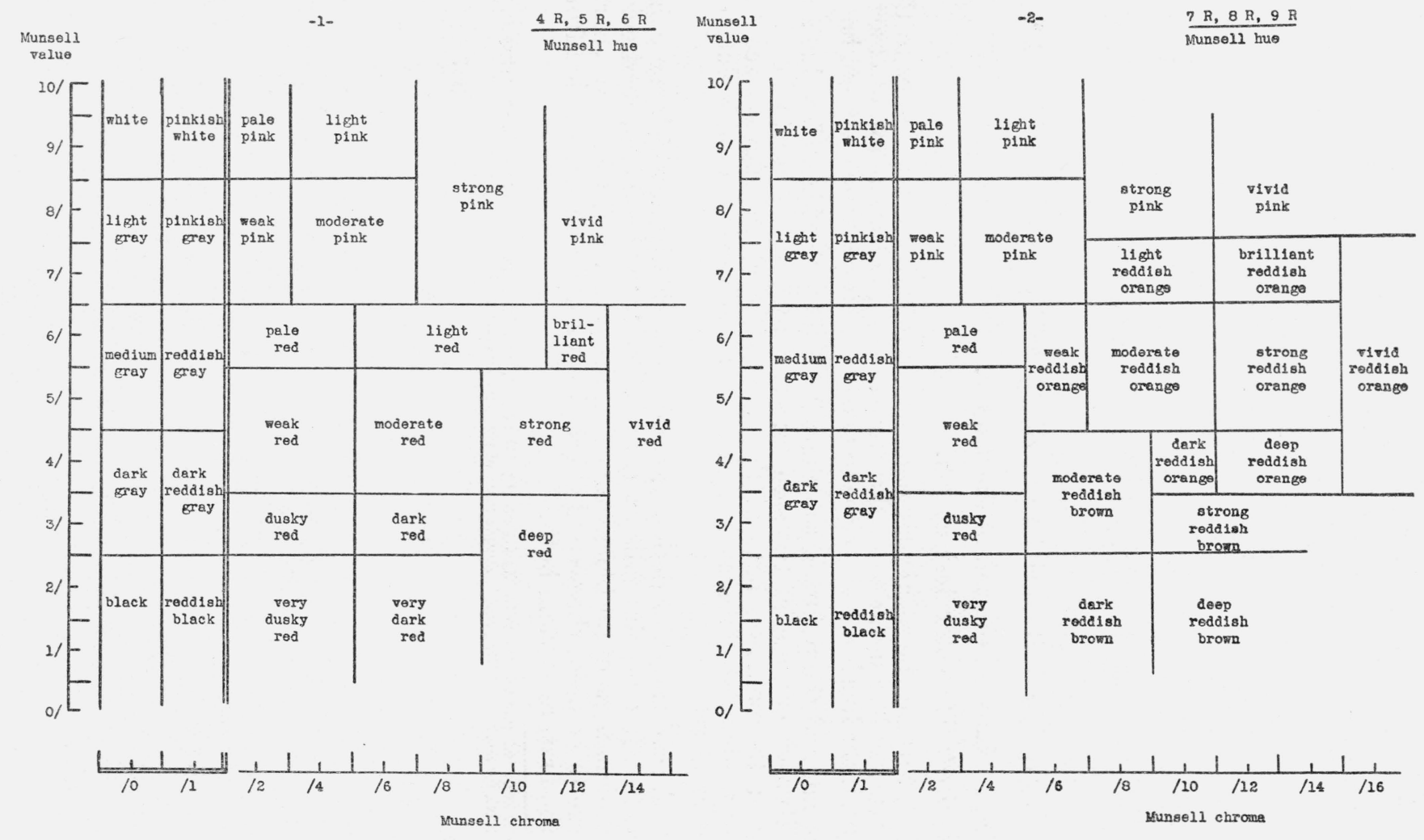


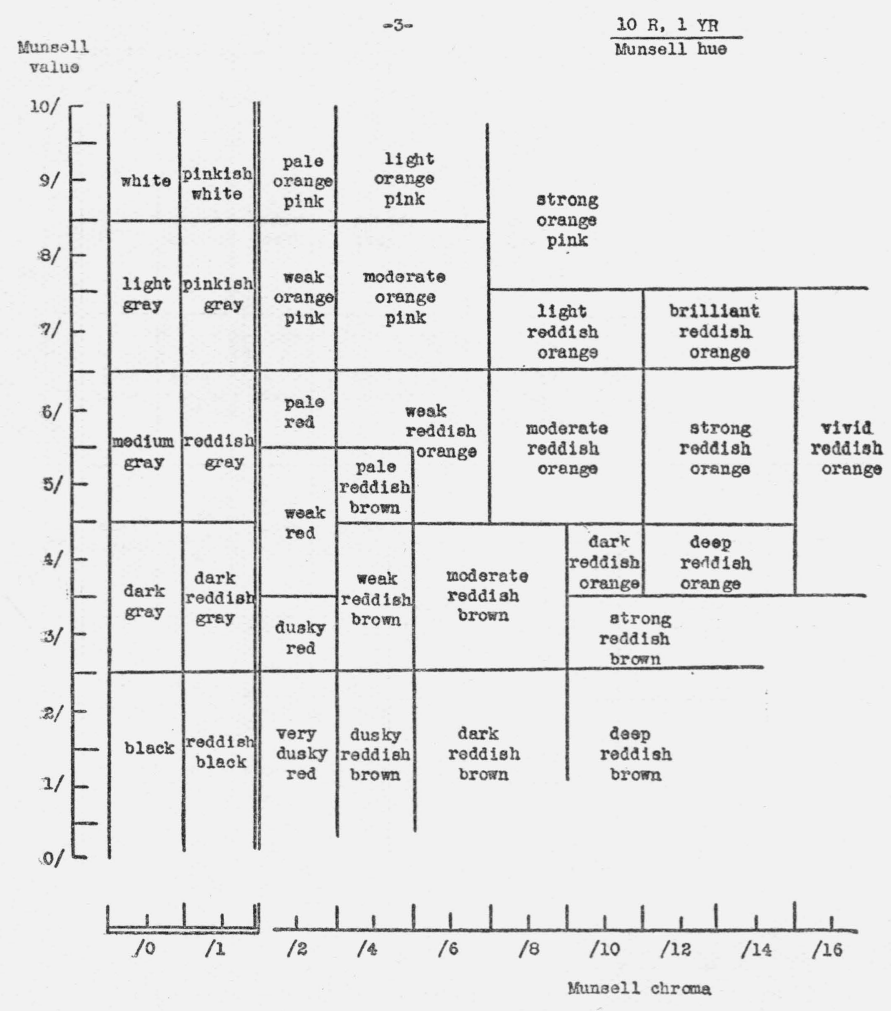

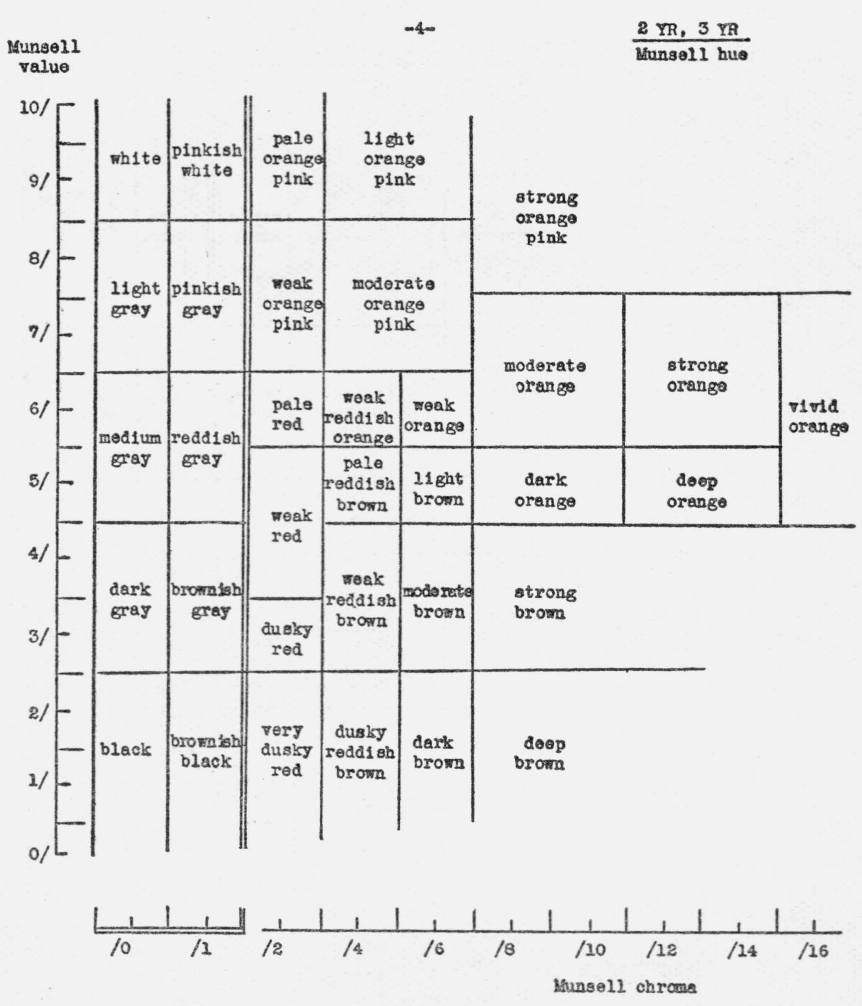

valve 

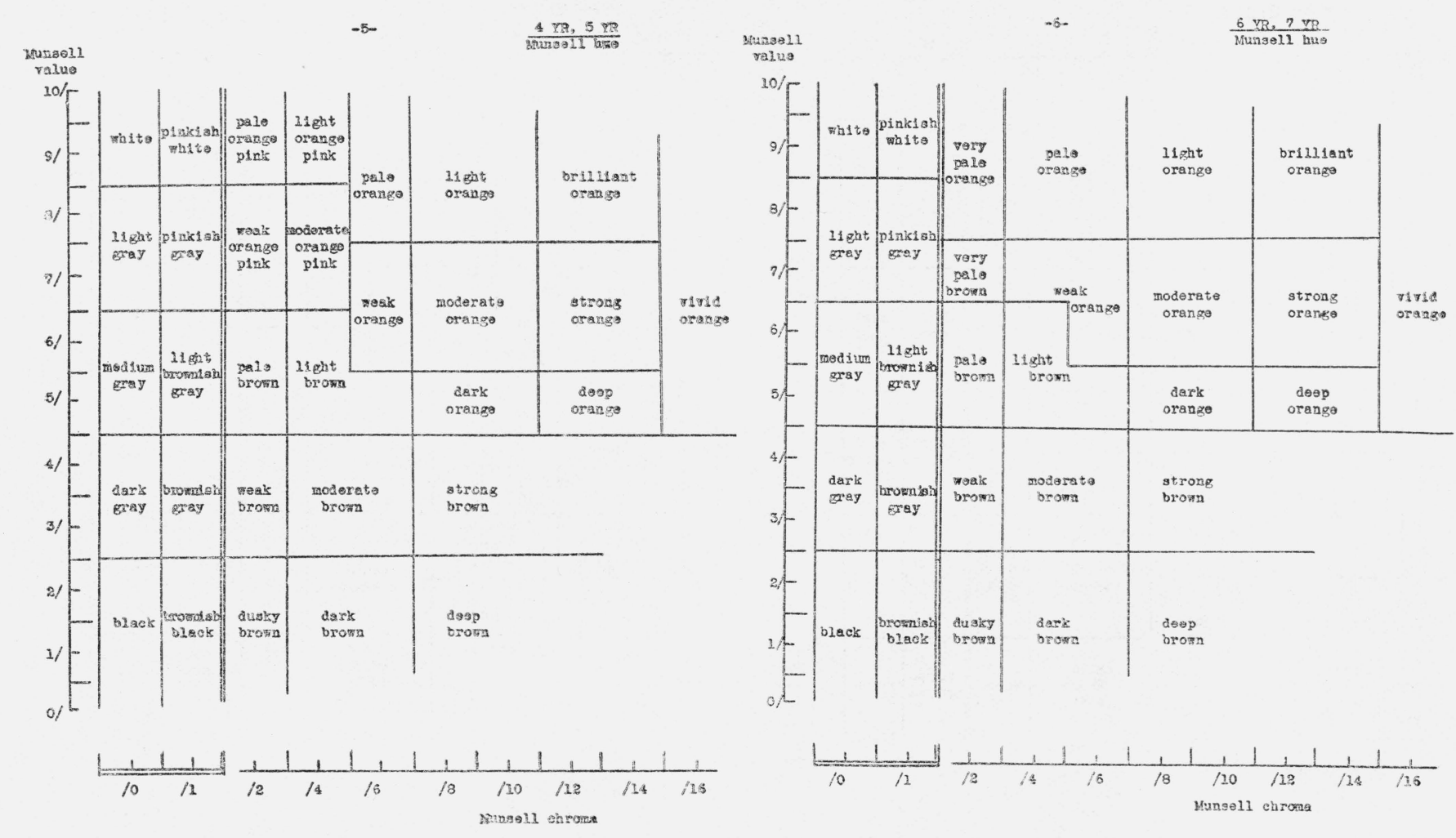

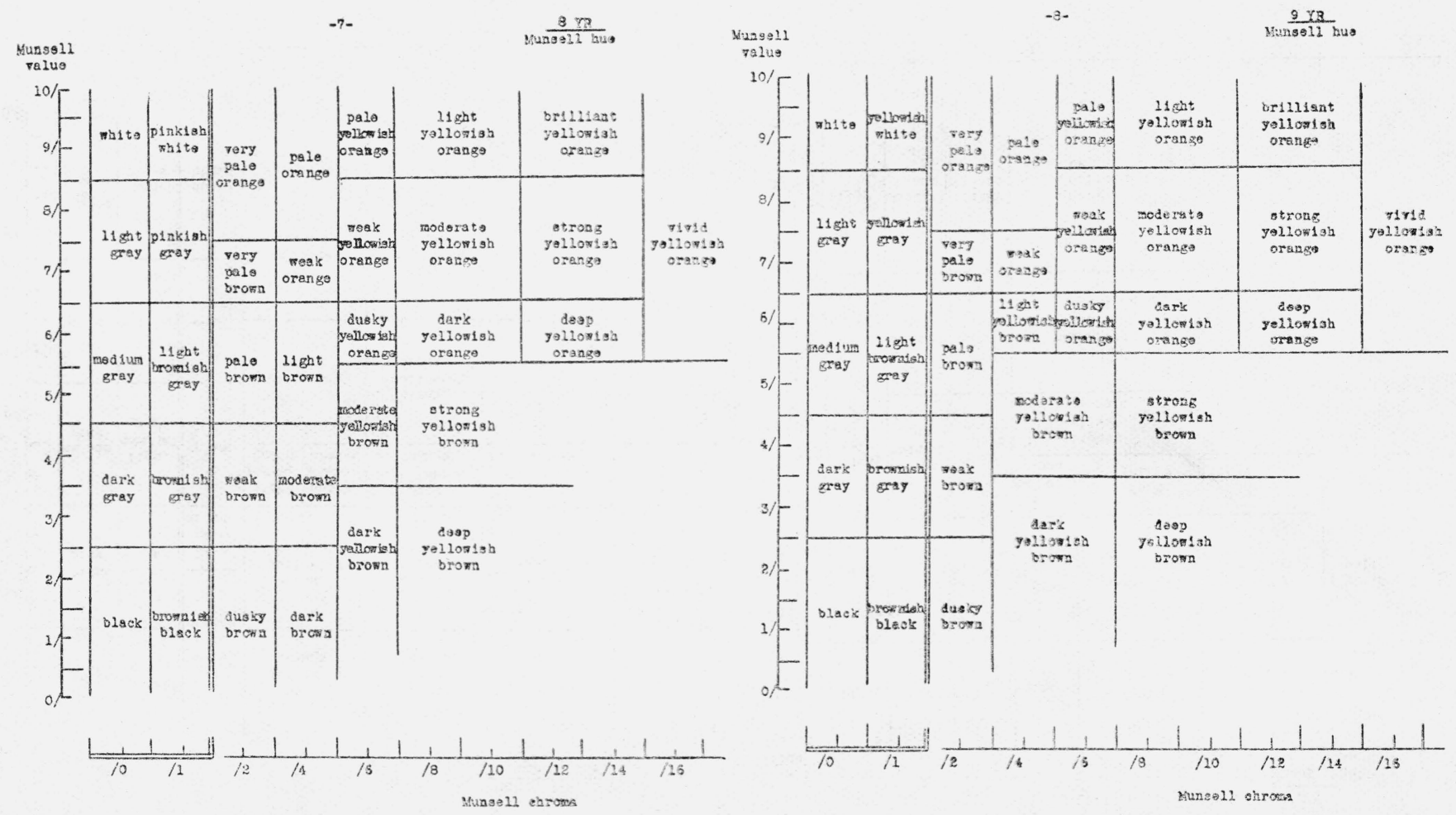

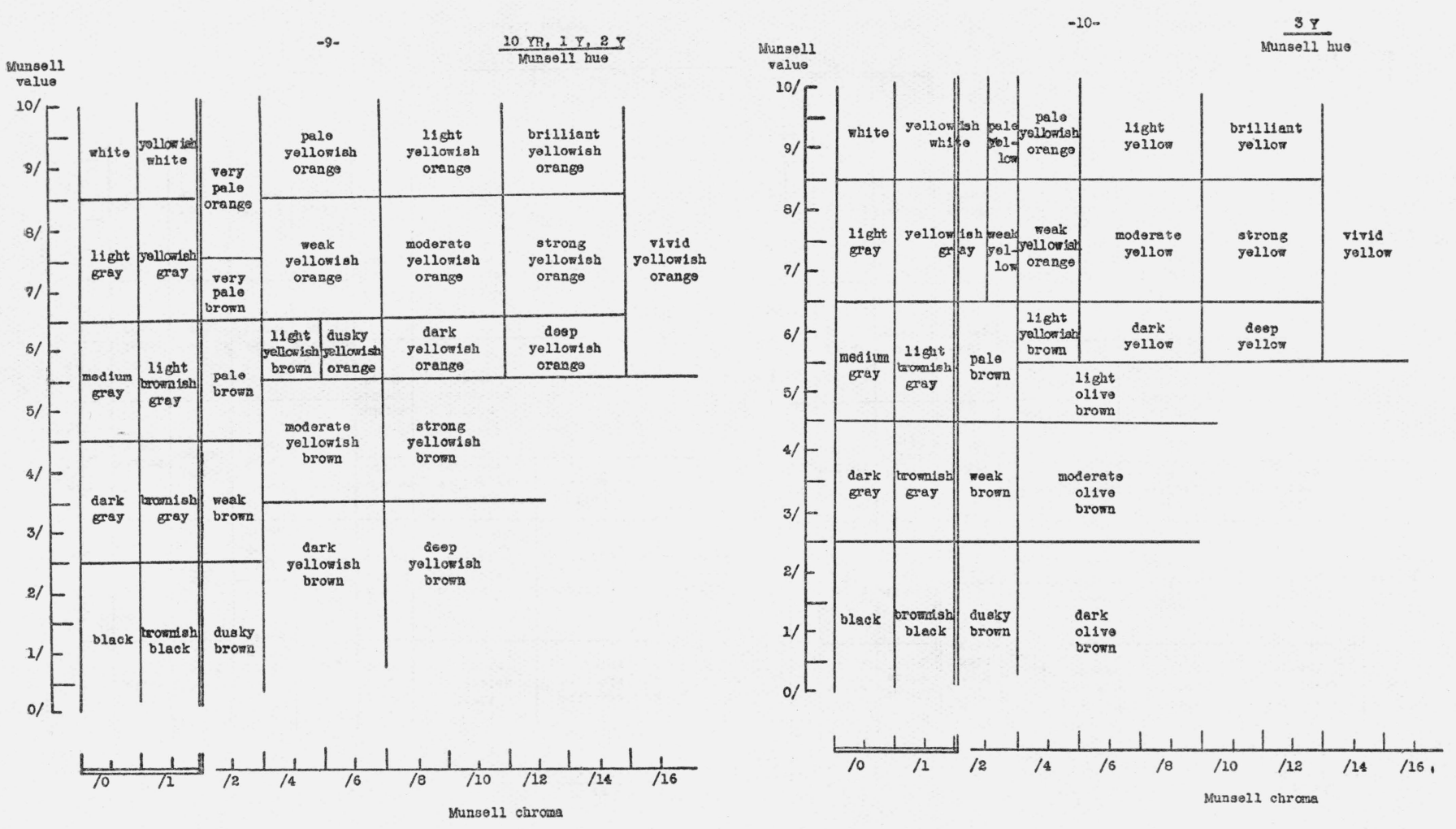

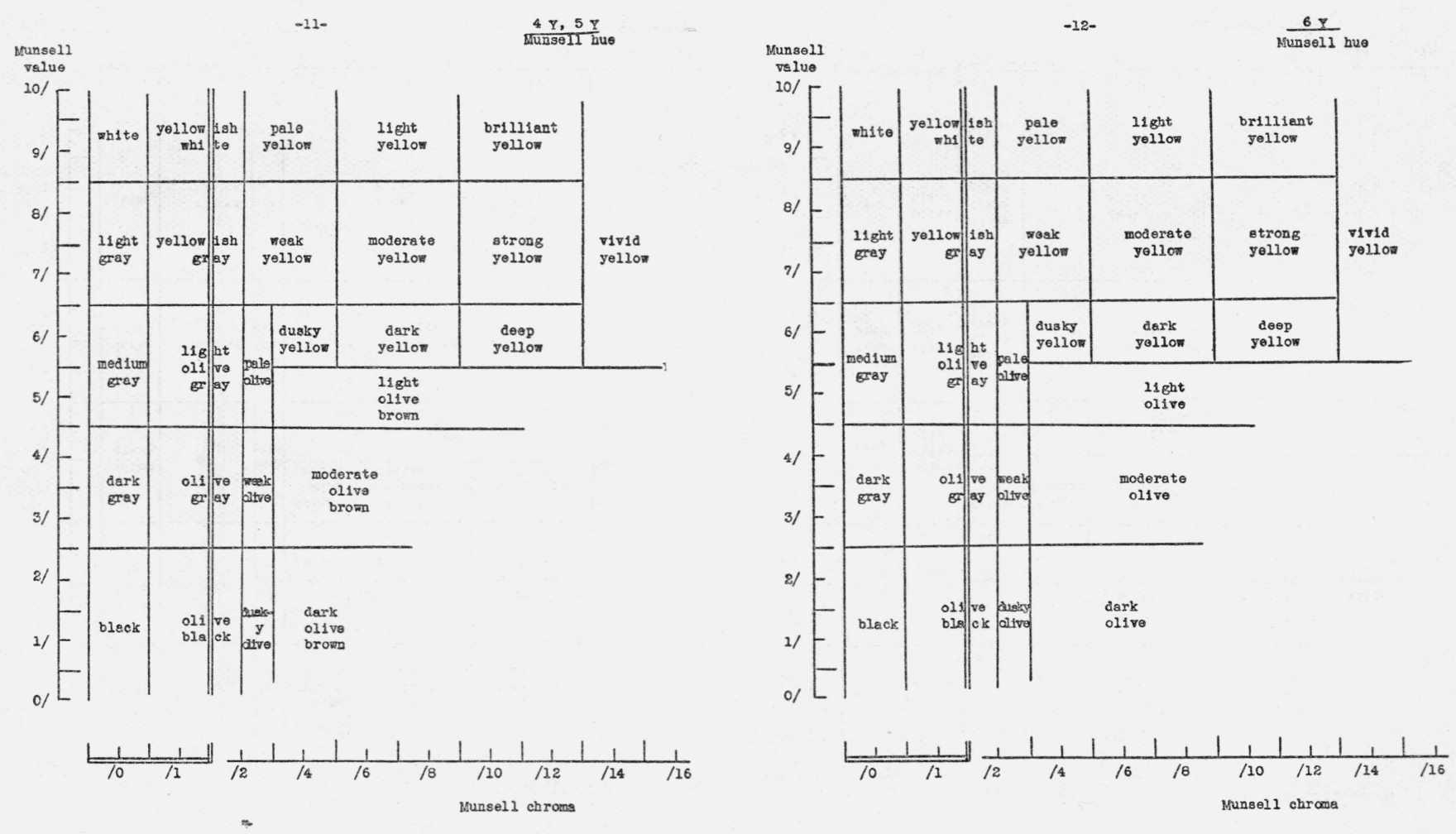

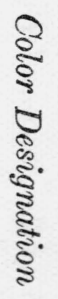


-13-

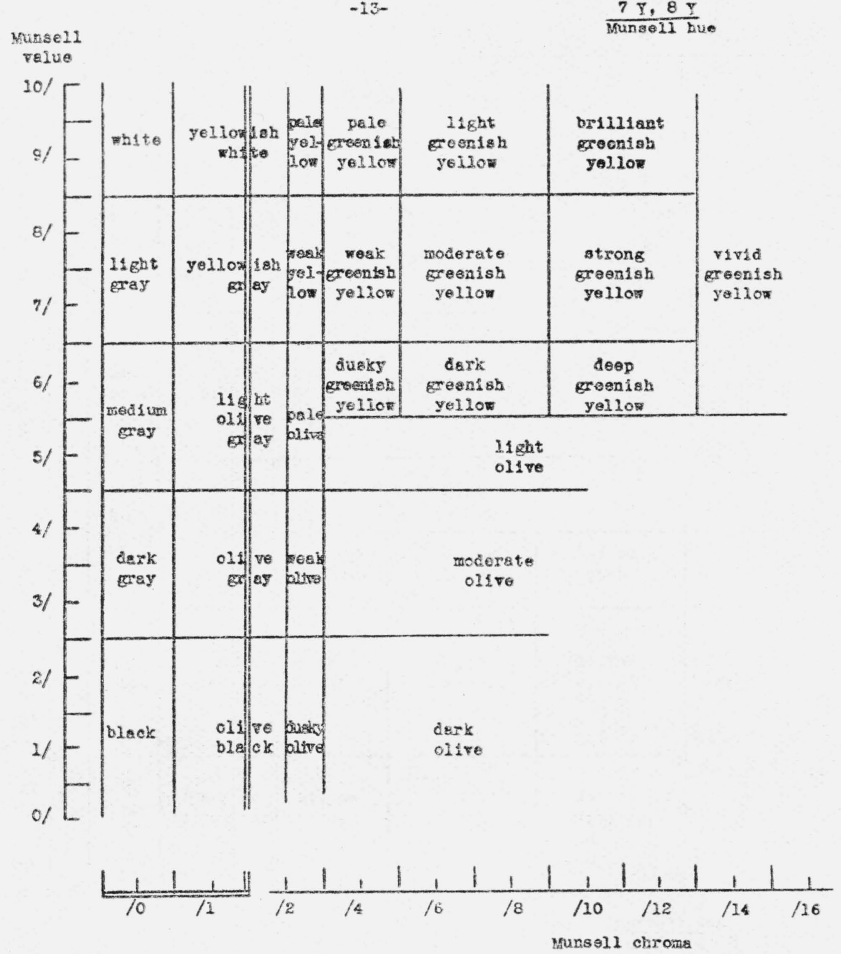

$-14-$

$9 \mathrm{Y}, 10 \mathrm{Y}, 1 \mathrm{GY}$

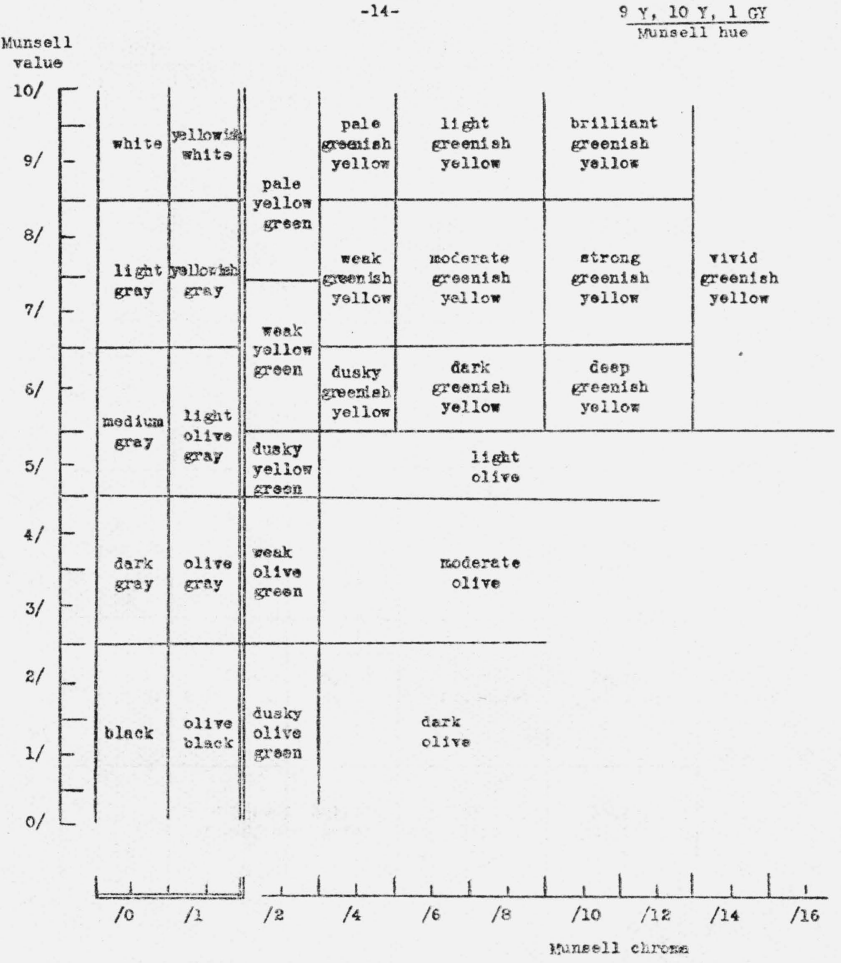



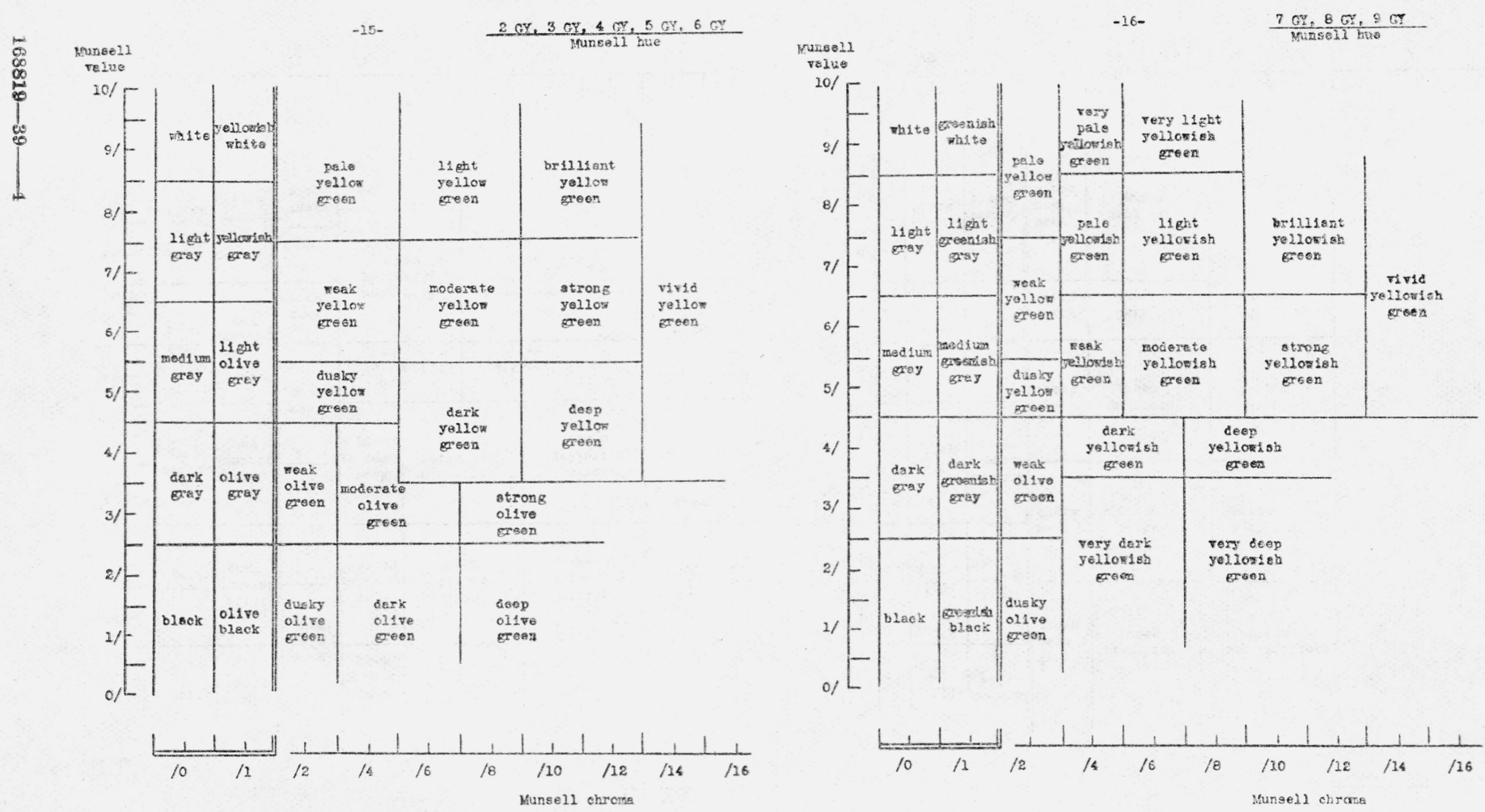

है 

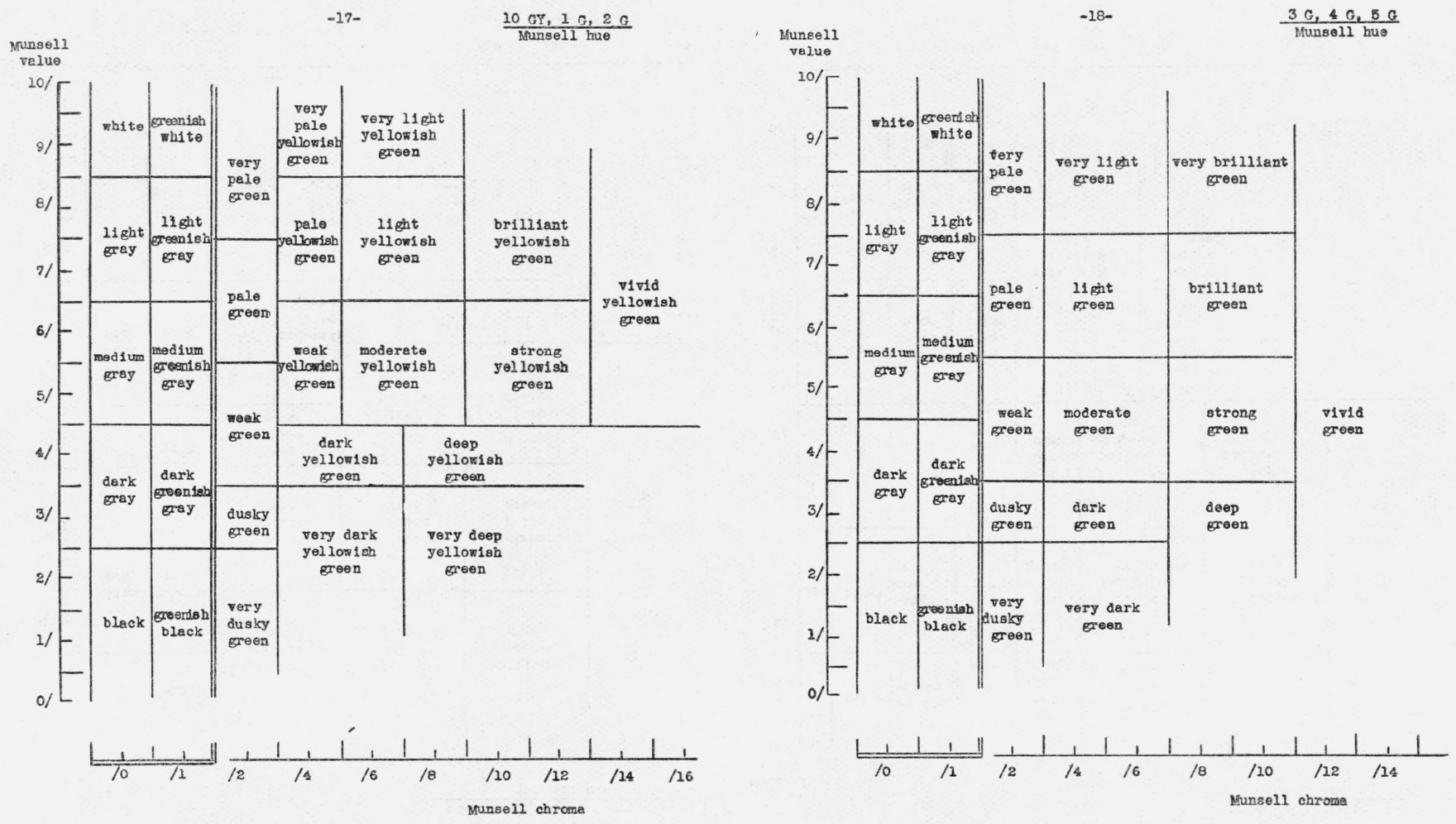

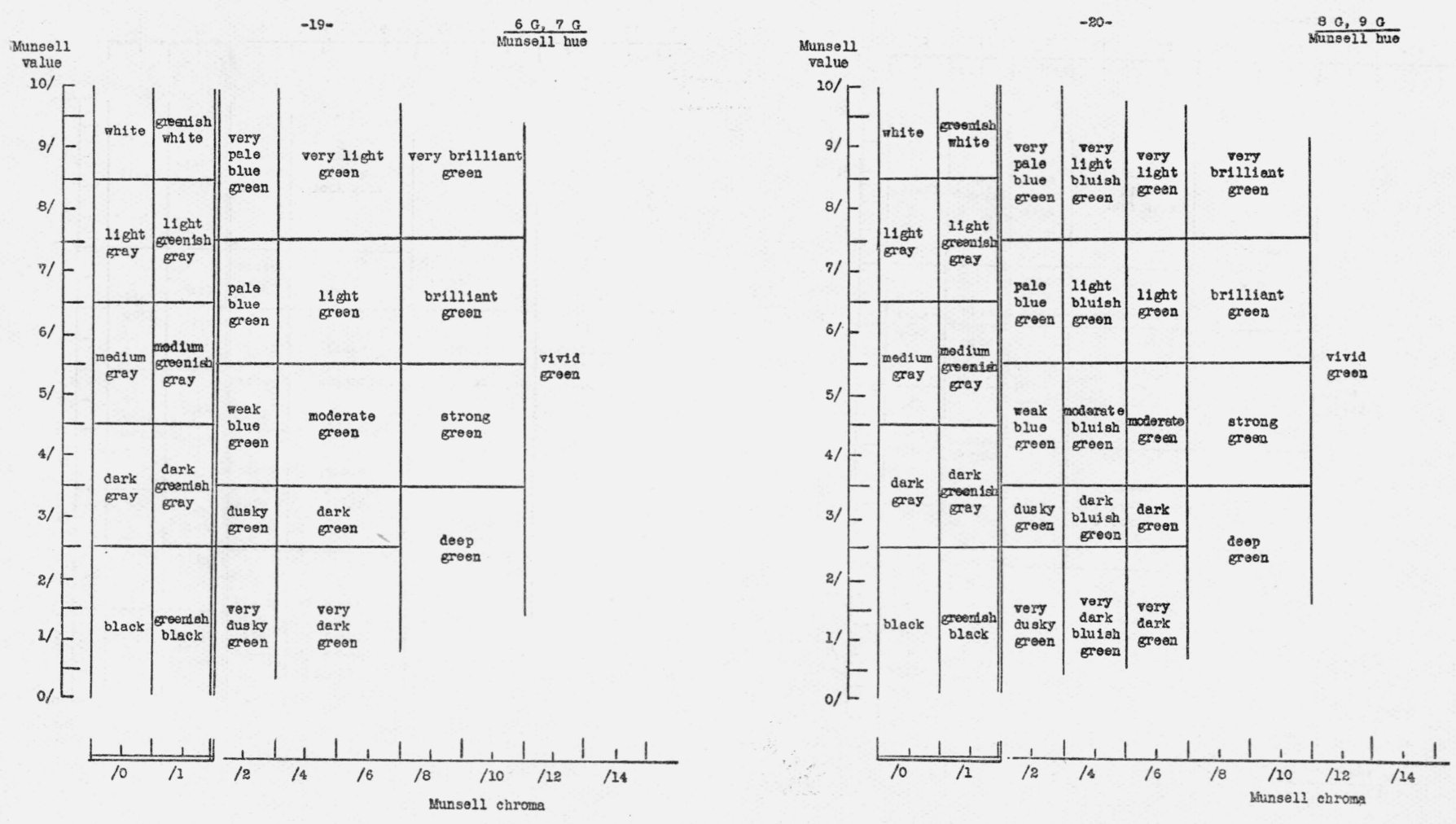

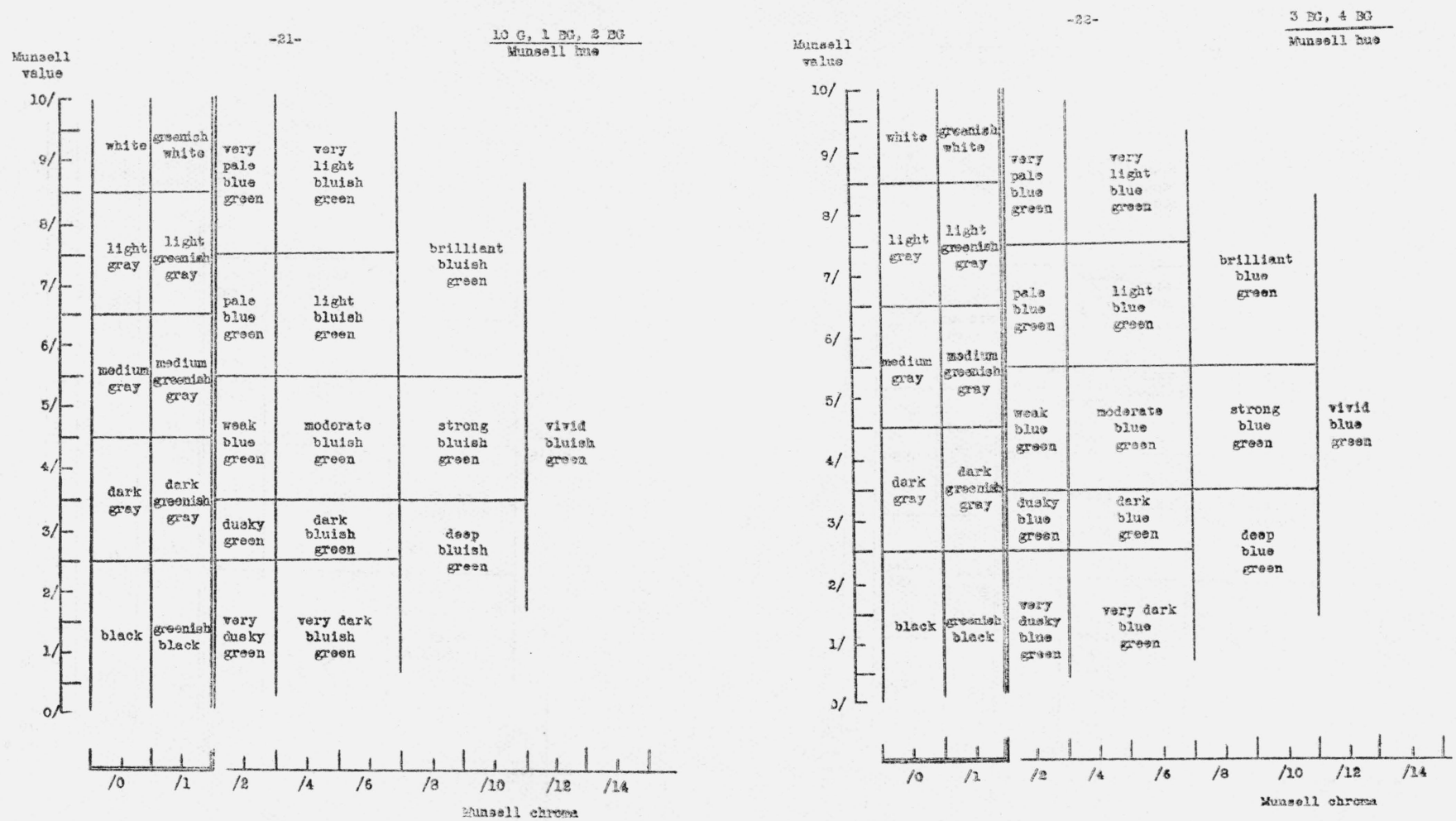



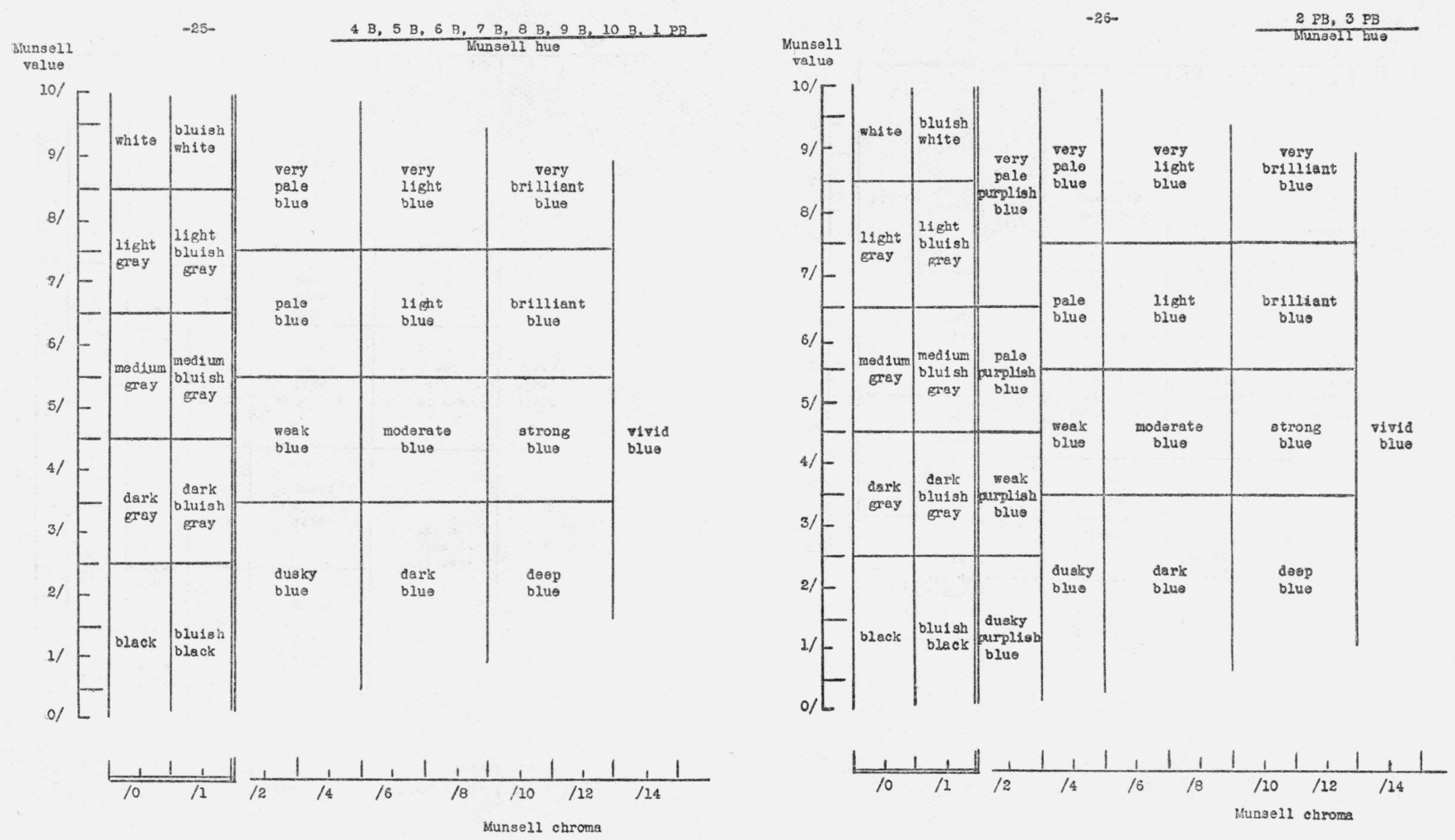

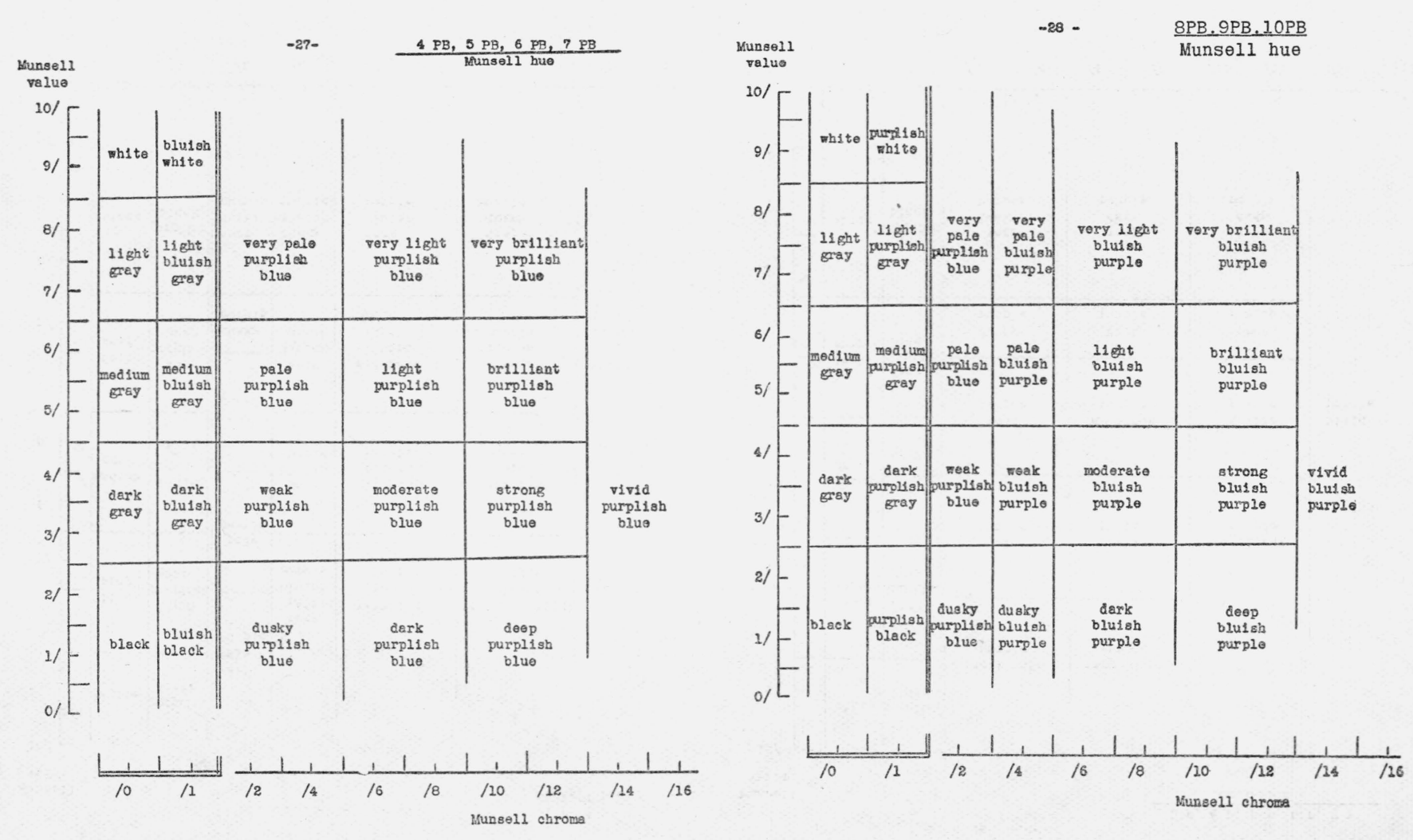

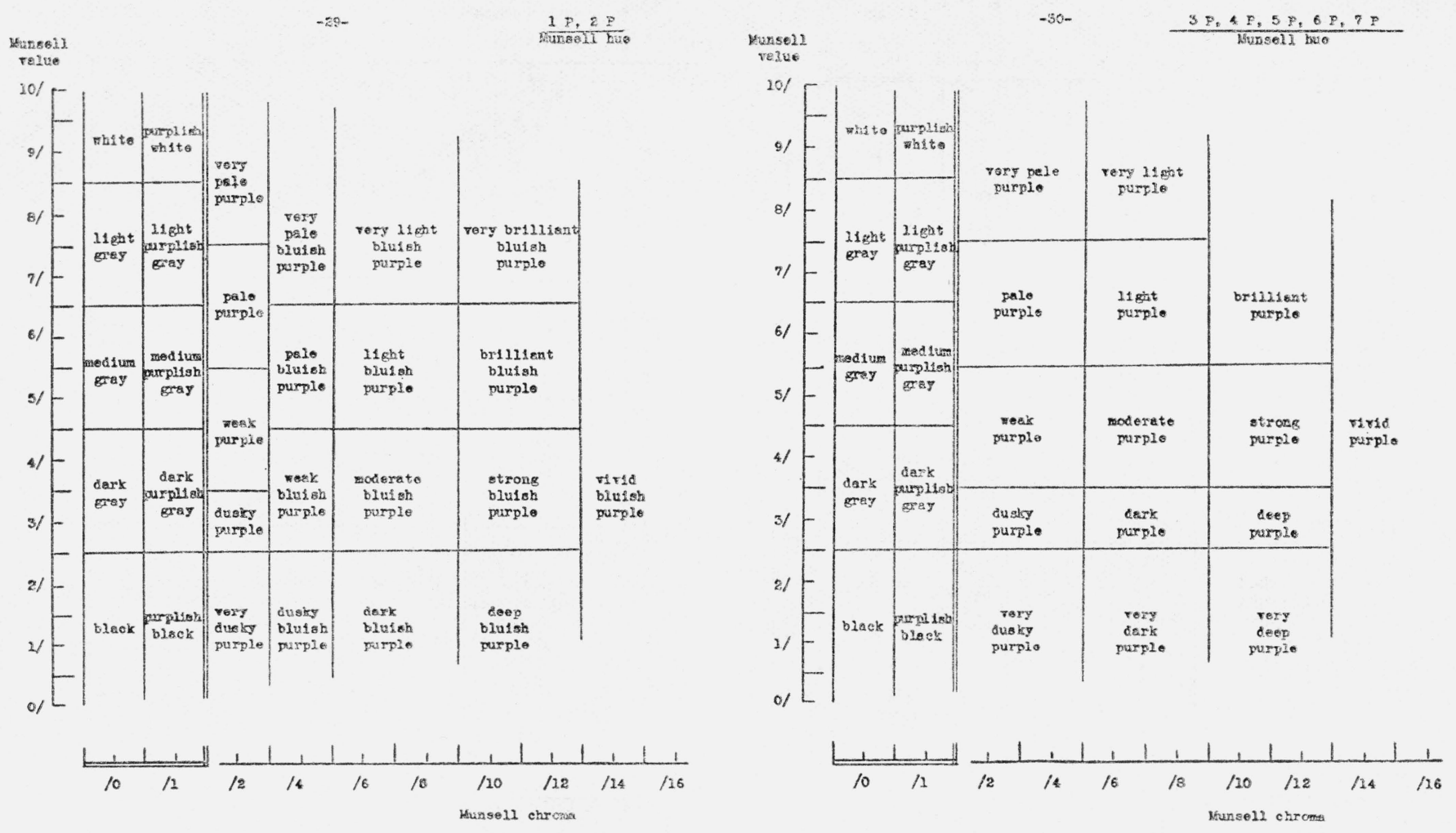

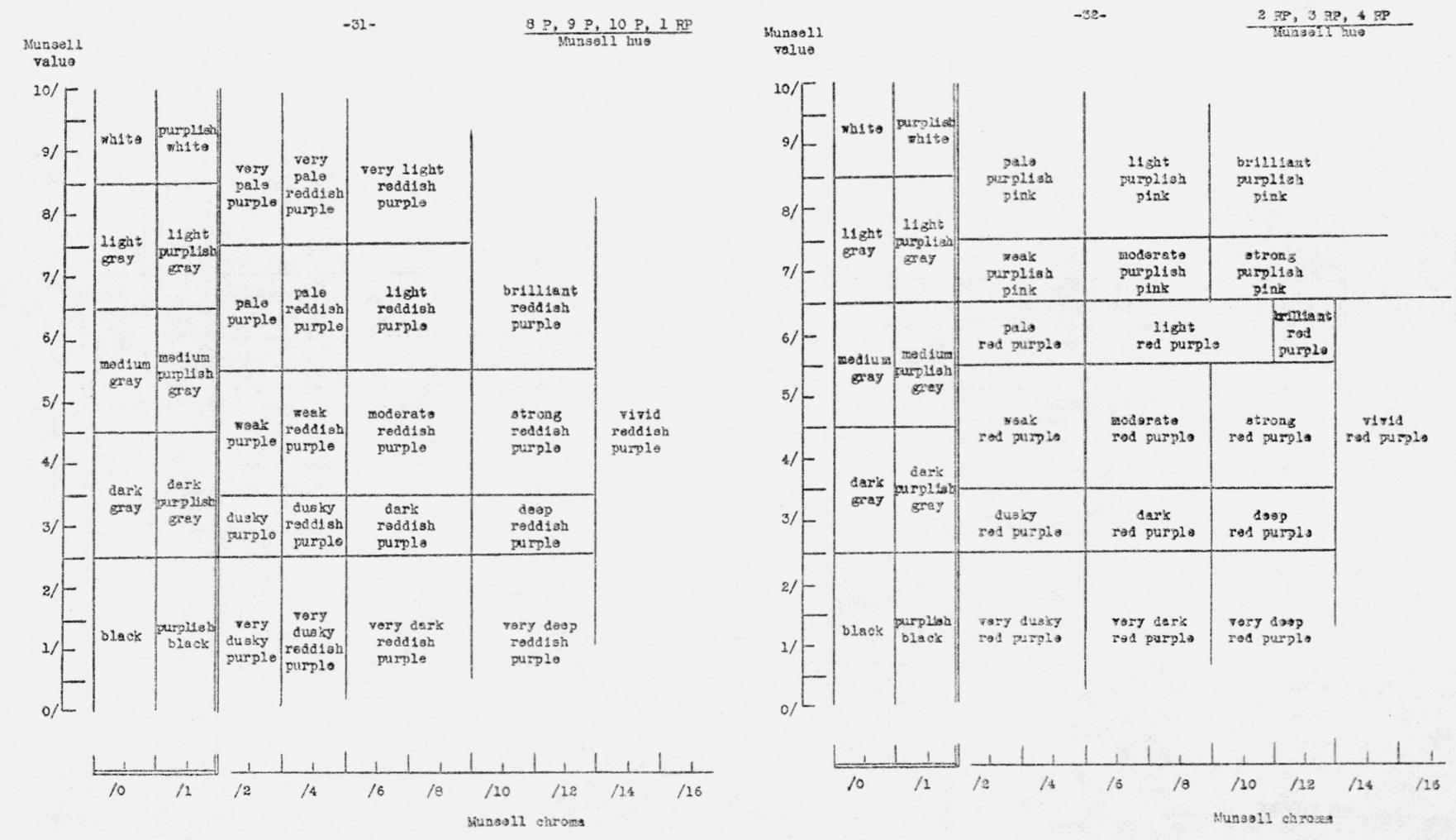

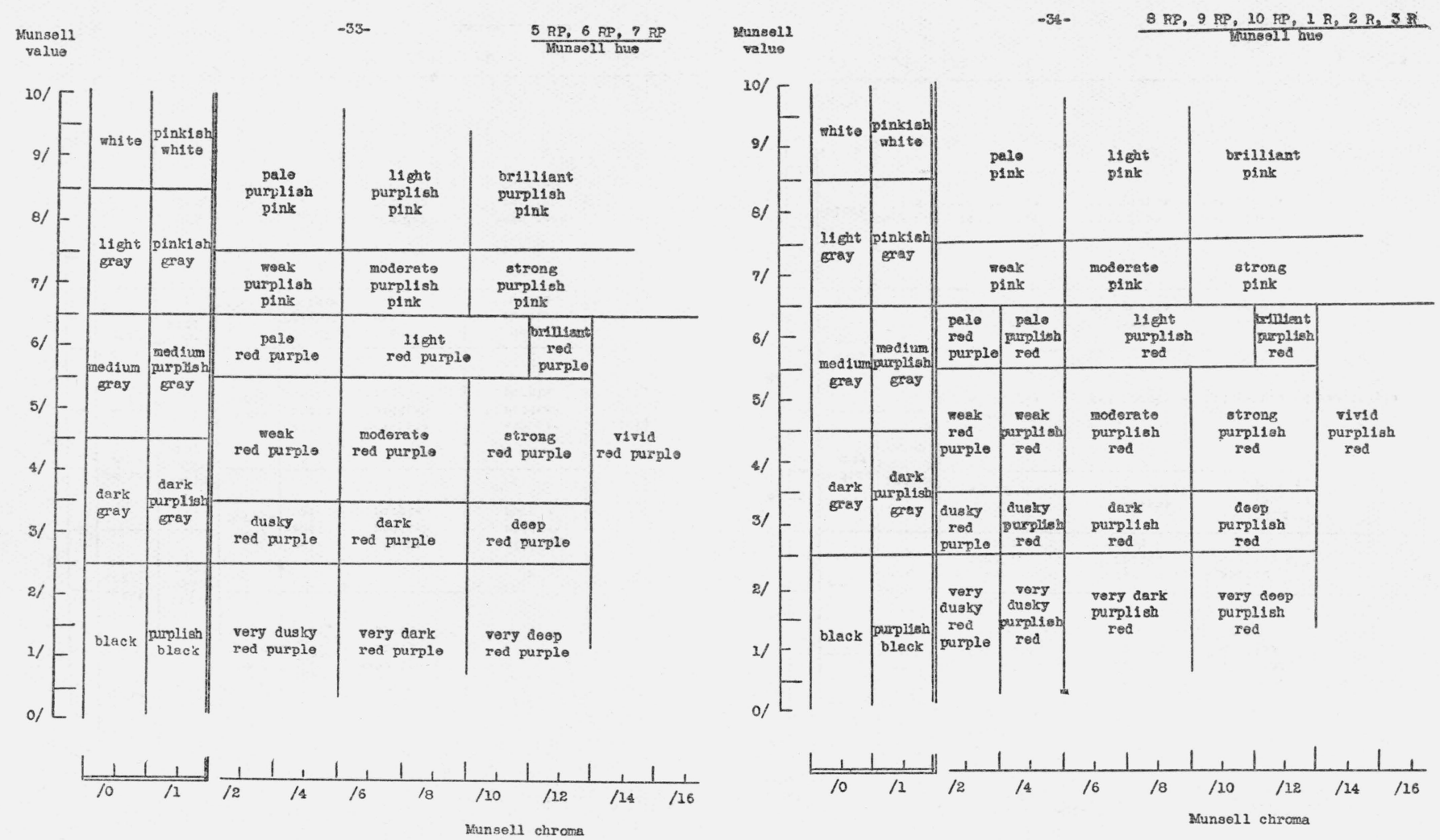

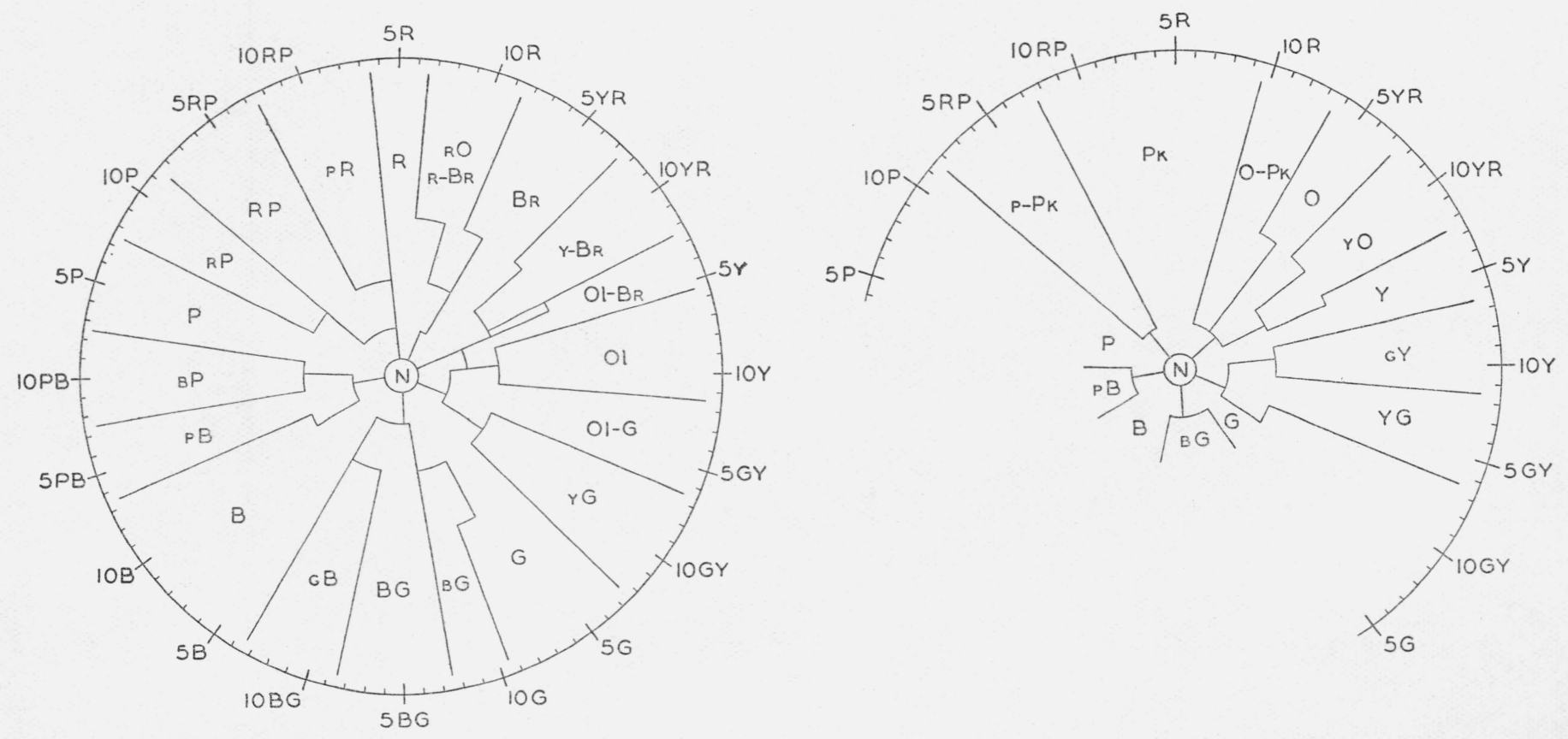